\title{
Susceptibility of Some Common Pecan Rootstocks to Infection by Xylella fastidiosa
}

\author{
Randy S. Sanderlin ${ }^{1}$ \\ Louisiana State University Agricultural Center Pecan Research-Extension \\ Station, 10300 Harts Island Road, Shreveport, LA 71115
}

Additional index words. Carya illinoinensis, pecan bacterial leaf scorch, pathogen graft transmission, mechanical inoculation

\begin{abstract}
Pecan [Carya illinoinensis (Wangenh.) K. Koch], a hardwood tree native to North America, is grown for commercial production of nuts in southeastern, central, and western regions of the United States. Pecan is also grown commercially in Mexico, South Africa, Australia, and some countries in South America. Pecan trees can be infected by the broad host range xylem-limited bacterial pathogen Xylella fastidiosa Wells et al. Infection incites a leaf scorch disease that can cause significant defoliation, reduced tree growth, and lower nut yield. Pecan cultivars are clonally propagated onto rootstocks grown from open-pollinated seed of selected cultivars. $X$. fastidiosa is transmitted at a high frequency from infected rootstocks into newly developing grafted trees. Rootstocks resistant to infection would be beneficial to pecan nurseries and pecan producers to prevent infection of young trees through grafting, especially when combined with hot-water treatment of scions to eliminate the pathogen. Some common rootstocks were tested for variation in susceptibility to infection using mechanical inoculation with the pathogen. No outstanding level of resistance to infection was detected among the seven rootstocks tested. The rootstocks from 'Curtis', 'Elliott', and 'Riverside' were less susceptible than one standard rootstock in the test ('VC1-68') and less susceptible than highly susceptible 'Cape Fear' rootstock. Conversely, the rootstocks from 'Apache', 'Moore', 'Stuart', and 'VC1-68' seed had a level of susceptibility to infection comparable to 'Cape Fear' and perhaps are not the best choice for rootstocks in geographic areas where $X$. fastidiosa is prevalent. The results of this research suggest that there is variation in rootstock susceptibility to infection by $X$. fastidiosa. The use of mechanical inoculation may facilitate identification of susceptibility categories of pecan rootstocks to the pecan bacterial leaf scorch pathogen.
\end{abstract}

Pecan [C. illinoinensis (Wangenh.) $\mathrm{K}$. Koch], a tree species native to the Mississippi River floodplain of North America, is cultivated for nut production across the southeastern United States, and other states including Texas, Oklahoma, Kanas, New Mexico, Arizona, and California (Graham and Gibson, 2005). Commercial pecan production also occurs in Mexico, South Africa, several South American countries, and Australia (Geisler, 2011). Pecan is susceptible to infection by $X$. fastidiosa ssp. multiplex resulting in the development of pecan bacterial leaf scorch (PBLS) disease (Melanson et al., 2012). The multiplex subspecies has a large host range, including numerous hardwood species, and causes disease in a variety of agriculturally important species including fruit and nut trees in the United States, and was recently reported to have infected olive trees in Italy (European Food Safety Authority, 2013; Hopkins and Purcell, 2002).

Received for publication 4 Mar. 2015. Accepted for publication 29 June 2015.

I thank Dr. L.J. Grauke for providing seed for rootstock production.

${ }^{1}$ Corresponding author. E-mail: rsanderlin@agcenter. lsu.edu.
In pecan, the disease causes defoliation, yield loss, and reduced growth of trees (Sanderlin and Heyderich-Alger, 2003). As with other hosts of this bacterium, the pathogen is transmitted to pecan through feeding by certain members of the Cicadellidae (leafhoppers) and Cercopidae (spittlebugs) insect families (Redak et al., 2004; Sanderlin and Melanson, 2010). In addition to insect transmission, the pathogen can be transmitted in pecan through infected rootstocks or scions (Sanderlin and Melanson, 2006). Once infection is established, the bacterium tends to become systemic in trees with chronic disease development. Because there is no effective treatment to eliminate the pathogen from infected trees, pecan trees infected through grafting will be affected by the disease throughout their life span, which can be several decades. In new orchards, graft transmission can provide the primary inoculum of $X$. fastidiosa, which may be subsequently spread by insect vectors. Without the establishment of the pathogen in an orchard through graft transmission, an orchard may escape several years before the pathogen is introduced by insect vectoring (Sanderlin, unpublished data).

It should be possible to reduce the incidence of PBLS by reduction of graft transmission from infected scions through the application of a hot-water treatment to dormant scions before grafting (Sanderlin and Melanson, 2008). The application of the hot-water treatment to pecan rootstock has not been tested and may be challenging because of the size of the rootstocks, and the need to treat the rootstock or grafted tree while dormant before transplanting into an orchard.

Pecan rootstocks are produced from open-pollinated seed of grafted cultivars. Certain cultivars are preferred as sources of seed for rootstocks based on size of the nuts, vigor of growth, and the effects on early tree growth and nut production following grafting to scions (Grauke and Thompson, 1995). The use of pecan rootstocks resistant to infection by $X$. fastidiosa combined with hot-water treatment of scions may provide a way for commercial pecan nurseries and pecan growers to establish new trees free of the pathogen. Rootstock resistance to $X$. fastidiosa infection has been identified in some other agricultural commodity hosts of the pathogen including, grapevine, almond, and peach (Gould et al., 1991; Gubler et al., 2008; Ledbetter and Rogers, 2009). Presently, there is no information available on the susceptibility of rootstocks used by the pecan nursery industry to infection by $X$. fastidiosa. The objective of this research was to test some of the pecan rootstocks commonly used by commercial nurseries for their degree of susceptibility to infection by the PBLS pathogen. This report provides the first data on pecan rootstock susceptibility to $X$. fastidiosa.

\section{Materials and Methods}

Seven rootstock types grown from openpollinated seed of the following cultivars were used in the study: 'Apache', 'Curtis', 'Elliott', 'Moore', 'Riverside', 'Stuart', and 'VC1-68'. Trees grown from seed of 'Cape Fear', which is not typically used as a rootstock, were included as a standard for comparison because of its known high degree of susceptibility as a cultivar and as nongrafted trees grown from 'Cape Fear' nuts (Littrell and Worley, 1975; Sanderlin and HeyderichAlger, 2000). Seeds for production of rootstocks from cultivars of 'Apache', 'Elliott', 'Moore', 'Riverside', and 'VC1-68' were supplied by the U.S. Department of Agriculture Pecan Breeding and Genetics Station at Somerville, TX. Seeds of cultivars 'Cape Fear', 'Curtis', and 'Stuart' were collected from trees at the LSU AgCenter Pecan Research-Extension Station, Shreveport, LA. The seeds were stored near $4{ }^{\circ} \mathrm{C}$ through the winter in moist vermiculite for stratification, and a single seed was planted into $25 \times$ $25 \mathrm{~cm}(\approx 9.5$-L volume $)$ plastic pots containing MetroMix 902 (Sungro, Agawam, MA) plant growth medium in Mar. 2013. The trees were grown for 1 year in a greenhouse and inoculated in 2014. At the time of inoculation, most trees were between 30 and $40 \mathrm{~cm}$ in height. 
Trees were observed for PBLS symptoms and assayed for the pathogen by enzymelinked immunosorbent assay (ELISA) before inoculation to confirm that $X$. fastidiosa was not detectable in the plants by serological assay. For ELISA, the two or three oldest leaves were removed from each tree and the rachises used for assay. All ELISAs conducted throughout the study were performed with a commercial kit for $X$. fastidiosa (Agdia Inc., Elkhart, IN). The preinoculation assays were done within a week before inoculation.

For each inoculation date, the inoculum was started from cultures stored at $-80{ }^{\circ} \mathrm{C}$ in $30 \%$ glycerol. Cultures were regenerated on a single petri plate of periwinkle wilt agar (PWA), and then transferred to fresh media several times to increase bacterial quantity. Each inoculum preparation was made up of the growth of three isolates produced in separate cultures. The isolates had been originally cultured from 'Cape Fear' pecan in 2005 and verified to be $X$. fastidiosa ssp. multiplex (Melanson et al., 2012). Cultures were maintained in darkness near $28{ }^{\circ} \mathrm{C}$. Inoculum was prepared by suspending the growth from 10- to 12-d-old cultures (usually five plates of each isolate) in $2.5 \mathrm{~mL}$ of sterile molecular grade water. Inoculum concentration was determined by serial 10 -fold dilution plating on PWA.

The inoculation procedure consisted of placing five $10-\mu \mathrm{L}$ quantity drops of inoculum along the main stem of the tree in or near the current season's growth. A dissecting needle was pushed through the drop into the stem. The needle was left in place until the drop was absorbed into the stem, usually less than a minute. Because the inoculations were made in the afternoons of hot summer days, an attempt was made to maintain the inoculum at a moderate temperature by keeping the inoculum vial in a Styrofoam container with a layer of ice that was covered by $\approx 1.5 \mathrm{~cm}$ layer of cotton cloth. The $10^{-1}$ dilution of the inoculum, which was kept at room temperature during the inoculation procedure, was plated on PWA following the inoculation period to verify that inoculum viability could be maintained for the length of the procedure.

Trees were removed from the greenhouse and placed outside in full sunlight before inoculation to increase transpiration. One tree of each rootstock type was inoculated followed by a second of each type and this order continued until five trees of each rootstock were inoculated. Each inoculation procedure took 2.5 to $3 \mathrm{~h}$. Trees stayed outside for about an hour after inoculation of the final tree and then all trees were returned to the greenhouse. Three sets of inoculations were performed with inoculations on 21 July, 5 Aug., and 29 Aug. 2014. At least 15 noninoculated trees of each rootstock type, maintained in the greenhouse, served as control trees, except for the 'Riverside' rootstock that had only five control trees because of poor seed germination.

Inoculated trees and control trees were observed at least weekly for development of
PBLS symptoms from their inoculation date until the trees went dormant in the greenhouses in late December.

Tissue for ELISA of the inoculated trees was collected initially at 9- to 12 -weeks post inoculation. Additional assays were done as symptoms developed. Trees in each of the three inoculation periods that had not previously assayed positive for infection were given a final ELISA at 17 to 22 weeks postinoculation. Five noninoculated control trees of each rootstock type were assayed 18 weeks after the first $X$. fastidiosa inoculation date.

For statistical analysis, inoculation dates were treated as experimental blocks, and the experimental design was a randomized complete block. Data were analyzed with the Tables function of SAS version 9.4. The Cochran-Mantel-Haenszel test was used for mean comparison to determine significant differences between infection values of the rootstocks.

\section{Results}

All of the 120 trees inoculated with $X$. fastidiosa tested negative for infection by ELISA before inoculation, and no PBLS symptoms were observed on any trees before inoculation. Throughout the test, no symptoms of scorch were observed on any of the control trees in the greenhouse, and the five control trees of each rootstock tested by ELISA for the pathogen were negative for infection.

The inoculum concentration for the 21 July and 5 Aug. inoculations was $\approx 10^{8}$ colony-forming units $(\mathrm{cfu}) / \mathrm{mL}$, and for the 29 Aug. inoculation date the concentration was $\approx 10^{7} \mathrm{cfu} / \mathrm{mL}$. The $10^{-1}$ dilution, which was maintained at room temperature during inoculation and applied to PWA after the tree inoculation was finished, always produced a concentrated film of bacterial growth, indicating that the viability of the pathogen suspension was maintained through the 2.5to 3-h inoculation time.

Symptoms on inoculated trees generally began to develop within 2 months; however, as is typical of PBLS, the time of symptom development on individual trees was variable and occurred over a period of $\approx 10$ (four trees) to 15 weeks (one tree). All eight of the pecan rootstocks were susceptible to infection by $X$. fastidiosa as determined by symptoms and ELISA. But there were statistical differences in the numbers of trees infected by the rootstock type (Table 1). The rootstock grown from seed of ' $\mathrm{VC} 1-68$ ' commonly used by nurseries to produce trees for use in the western U.S. pecan production region with 14 of 15 inoculated plants determined to be infected was infected at a statistically higher percentage than five of the standard rootstocks and was comparable in number of infected trees to the highly susceptible 'Cape Fear' seed rootstock (Table 1). Symptom production on ' $\mathrm{VC} 1-68$ ' rootstock was often more rapid and often more severe than on the other types including 'Cape Fear'. The rootstocks from 'Apache', 'Moore', and 'Stuart' were also not significantly different from 'Cape Fear'. Even though rootstocks from seed of 'Apache' and 'Moore' had a lower incidence than 'Cape Fear' type rootstocks, they still each had higher than a $50 \%$ infection level. The rootstock grown from 'Curtis', 'Elliott', and 'Riverside' had a significantly lower incidence of infection than 'Cape Fear' and 'VC1-68'; but were not lower than any of the other rootstocks tested (Table 1).

The majority $(86 \%)$ of the trees of that were positive for infection by ELISA either had symptoms of PBLS when the positive assay tissue was collected or developed symptoms later after the positive assay. There were 10 trees that assayed positive for $X$. fastidiosa infection by ELISA that were not recorded with PBLS symptoms during the duration of this work. Within rootstock type the number of infected trees that failed to show symptoms during the observation period was 0 to 3 .

\section{Discussion}

The work reported here serves as a starting point in the attempt to develop knowledge on the susceptibility of pecan rootstocks to infection by $X$. fastidiosa. Ideally, if rootstocks with useful levels of resistance to infection can be identified, their use will reduce the probability of nursery produced trees being infected at the time of sale as a result of graft transmission through infected rootstocks. The results indicate there are differences across open-pollinated rootstock types in susceptibility to infection by $X$. fastidiosa .

Under natural conditions, trees to be used for rootstocks would be infected by insect transmission of the pathogen. In this test, infection challenge was by mechanical inoculation with high bacterial concentrations. It is not known exactly how susceptibility to mechanical inoculation compares with susceptibility to vector transmission. Plant species that may not be naturally susceptible to infection by a specific subspecies of $X$. fastidiosa may occasionally be infected with that subspecies through mechanical inoculation (Sanderlin, unpublished data). Mechanical inoculation may therefore present a severe challenge of a plant's inherent resistance system. Consequently, resistance detected through mechanical inoculation may actually be at a higher functional level in nature. Insect transmission efficiency studies with $X$. fastidiosa have demonstrated a wide range of transmission rates and are affected by numerous variables (Redak et al., 2004), but generally insect transmission occurs at a lower rate than infection by mechanical inoculation (Almeida and Purcell, 2003; Rashed et al., 2011). In this test, $73 \%$ of trees grown from open-pollinated 'Cape Fear' seed were infected by mechanical inoculation compared with an insect transmission rate of $11 \%$ to $22 \%$ when various 
Table 1. Infection incidence of pecan rootstock types mechanically inoculated with Xylella fastidiosa ssp. multiplex. ${ }^{\mathrm{z}}$

\begin{tabular}{lcccc}
\hline Rootstock $^{y}$ & Inoculation 21 July $^{\mathrm{x}}$ & Inoculation 5 Aug. & Inoculation 29 Aug. & Total \\
\hline Apache & $4 / 5^{\mathrm{w}}$ & $4 / 5$ & $1 / 5$ & $9 / 15 \mathrm{abc}^{\mathrm{v}}$ \\
Cape Fear & $3 / 5$ & $5 / 5$ & $3 / 5$ & $11 / 15 \mathrm{ab}$ \\
Curtis & $1 / 5$ & $2 / 5$ & $1 / 5$ & $4 / 15 \mathrm{c}$ \\
Elliott & $1 / 5$ & $4 / 5$ & $1 / 5$ & $6 / 15 \mathrm{c}$ \\
Moore & $2 / 5$ & $3 / 5$ & $3 / 5$ & $8 / 15 \mathrm{~b} \mathrm{c}$ \\
Riverside & $2 / 5$ & $3 / 5$ & $0 / 5$ & $5 / 15 \mathrm{c}$ \\
Stuart & $2 / 5$ & $3 / 5$ & $2 / 5$ & $7 / 15 \mathrm{~b} \mathrm{c}$ \\
VC1-68 & $5 / 5$ & $5 / 5$ & $4 / 5$ & $14 / 15 \mathrm{a}$ \\
\hline
\end{tabular}

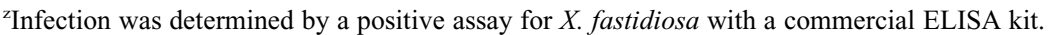

${ }^{y}$ Rootstocks grown from open-pollinated seed of indicated cultivars.

${ }^{x}$ The date that trees were inoculated in 2014 .

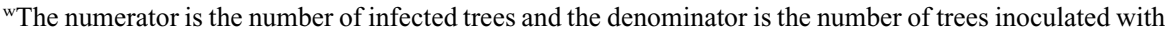
a suspension of the bacterium.

${ }^{v}$ Means followed by different letters are significantly different by the Cochran-Mantel-Haenszel test $(P \leq$ $0.05)$.

vectors were exposed to infected pecan trees then transferred to trees from open-pollinated 'Cape Fear' seed (Sanderlin and Melanson, 2010).

Mechanical inoculation has been used previously to evaluate pecan cultivar and seedling susceptibility with results similar to an orchard survey for the disease (Sanderlin, 2005). Mechanical inoculation has also been used to identify resistant rootstock in citrus. A citrus rootstock resistant to citrus variegated chlorosis (CVC) disease was identified through mechanical inoculation tests. The rootstock 'Rangpur' did not produce symptoms of CVC after it was mechanically inoculated and apparently supported only a low population of $X$. fastidiosa. 'Rangpur' was not considered a significant source of inoculum for insect transmission (Garcia et al., 2012).

Symptom development is not always a quick way to detect infection as symptoms can be transitory with symptomatic leaflets falling off and the reoccurrence of foliar symptoms in the same growth period delayed or absent. Possible explanations for the lack of detection of symptoms in $14 \%$ of the trees that ELISA indicated were infected include failure to observe symptoms before defoliation of the affected leaflets and potential of ELISA to detect the pathogen at titers insufficient for PBLS symptom development. In previous greenhouse tests, pecan trees recorded as infected by ELISA and maintained for a least two summers always produced symptoms at some point during the two growth periods. It is likely that the symptomless infected trees recorded in this work would also produce PBLS symptoms if maintained for another year.

The results from this greenhouse test using mechanical inoculation are in general agreement with occurrence of PBLS in nongrafted rootstock trees in an orchard that was monitored for spread of PBLS for 10 years (Sanderlin, unpublished data). The orchard contained a mixture of cultivars and nongrafted trees of five of the rootstocks used in the test reported here. The incidence of PBLS in the nongrafted rootstock trees in this orchard after 10 years was similar to the incidence of infection of the same rootstocks used in the test reported here. Cultivar Apache seed rootstock trees had the highest incidence of PBLS with $42 \%$ of its trees infected, followed by trees from seed of 'Riverside' (33\%), and 'Moore' (19\%). The nongrafted trees of 'Curtis' and 'Elliott' seed had no trees identified with PBLS after 10 years in this orchard. These data correlate well with the results of this inoculation test in which the rootstocks from 'Curtis' had the lowest percentage infection by mechanical inoculation. The generally greater infection rates with mechanical inoculation compared with infection by natural insect vectoring over a decade adds support to the supposition that mechanical inoculation presents a severe challenge to evaluate resistance to infection by $X$. fastidiosa.

The data suggest practical benefits would result from intensive screening of pecan rootstocks for resistance to $X$. fastidiosa. With wider screening of additional rootstock types, it may be possible to identify rootstocks with greater resistance to infection than that detected in this initial work. In addition, such testing could aid the pecan industry in identifying rootstocks with extreme susceptibility to infection. In this research, rootstocks of 'VC1-68' seed were infected at even a higher percentage than nongrafted 'Cape Fear', known to have a high level of susceptibility (Sanderlin and Heyderich-Alger, 2000). Even though 'VC1-68' has greater vigor than the other rootstocks tested with a mean aboveground growth of $60.8 \mathrm{~cm}$ compared with $53.2 \mathrm{~cm}$ for the other seven rootstocks combined when growth was measured during dormancy in Jan. 2015, it should not be used as a cultivar for rootstock production in the southeastern United States because of the higher probability of infection of these rootstocks in nurseries.

Resistance to $X$. fastidiosa infection in pecan rootstocks does not appear to be conferred to scions grafted onto to them. In the orchard study of PBLS spread where cultivars were grafted to some of the rootstocks tested in this study, 'Cape Fear' trees grafted to rootstock produced from 'Curtis' seed did not have a lower incidence of disease than trees grafted to the more susceptible rootstock type of 'Apache' (Sanderlin, unpublished data). The lack of resistance transfer from rootstocks to scions also exists in grapevine (Gubler et al., 2008; $\mathrm{Xu}$ et al., 2002). Nonetheless, the production of trees initially free of infection from graft transmission through infected rootstocks and pathogen free scions should be an advantage in new orchard establishment and may result in several years of growth and nut production before the pathogen is introduced into the orchard by insect vector transmission.

\section{Literature Cited}

Almeida, R.P. and A.H. Purcell. 2003. Biological traits of Xylella fastidiosa strains from grapes and almonds. Appl. Environ. Microbiol. 69:7447-7452.

European Food Safety Authority. 2013. Statement of EFSA on host plants, entry and spread pathways and risk reduction options for Xylella fastidiosa Wells et al. EFSA Journal. 11:3468

Garcia, A.L., S.C. Torres, M. Heredia, and S.A. Lopes. 2012. Citrus responses to Xylella fastidiosa infection. Plant Dis. 96:12451249.

Geisler, M. 2011. Pecans. Agricultural Marketing Resource Center. 4 Feb. 2015. <http://www. agmrc.org/commodities_products/nuts/pecans/>.

Gould, A.B., W.J. French, J.H. Aldrich, B.V. Brodbeck, R.F. Mizell, III, and P.C. Andersen. 1991. Rootstock influence on occurrence of Homalodisca coagulata, peach xylem fluid amino acids, and concentrations of Xylella fastidiosa. Plant Dis. 75:767-770.

Graham, C.J. and A. Gibson. 2005. Louisiana pecan industry: Past and future. Proc. Southeastern Pecan Growers Assoc. 98:72-77.

Grauke, L.J. and T.E. Thompson. 1995. Rootstock development, p. 167-175. In: M.W. Smith, W. Reid, and B.W. Wood (eds.). Sustaining Pecan Productivity into the $21 \mathrm{st}$ Century. Second National Pecan Workshop Proceedings. U.S. Department of Agriculture, Agricultural Research Service, Ser. Pub. ARS-1995-3.

Gubler, W.D., R.J. Smith, L.G. Varela, S. Vasquez, J.J. Stapleton, and A.H. Purcell. 2008. UC management guidelines for Pierce's disease of grape. 4 Feb. 2015. < http://www.ipm.ucdavis. edu/PMG/r302101211.html>

Hopkins, D.L. and A.H. Purcell. 2002. Xylella fastidiosa: Cause of Pierce's disease of grapevine and other emergent diseases. Plant Dis. 86:1056-1066.

Ledbetter, C.A. and E.E. Rogers. 2009. Differential susceptibility of Prunus germplasm (Subgenus Amygdalus) to a California isolate of Xylella fastidiosa. HortScience 44:1928-1931.

Littrell, R.H. and R.E. Worley. 1975. Relative susceptibility of pecan cultivars to fungal leaf scorch and relationship to mineral composition of foliage. Phytopathology 65:717-718.

Melanson, R.A., R.S. Sanderlin, A.R. McTaggart, and J.H. Ham. 2012. A systematic study reveals that Xylella fastidiosa strains from pecan are part of $X$. fastidiosa subsp. multiplex. Plant Dis. 96:1123-1134.

Rashed, A., M.P. Daugherty, and R.P. Almeida. 2011. Grapevine genotype susceptibility to Xylella fastidiosa does not predict vector transmission success. Environ. Entomol. 40:11921199. 
Redak, R.A., A.H. Purcell, J.R. Lopes, M.J. Blua, R.F. Mizel, and P.C. Anderson. 2004. The biology of xylem fluid-feeding insect vectors of Xylella fastidiosa and their relation to disease epidemiology. Annu. Rev. Entomol. 49:243-270.

Sanderlin, R.S. 2005. Cultivar and seedling susceptibility to pecan bacterial leaf scorch caused by Xylella fastidiosa and graft transmission of the pathogen. Plant Dis. 89:446449 .
Sanderlin, R.S. and K.I. Heyderich-Alger. 2000. Evidence that Xylella fastidiosa can cause leaf scorch disease of pecan. Plant Dis. 84:12821286.

Sanderlin, R.S. and K.I. Heyderich-Alger. 2003. Effects of pecan bacterial leaf scorch on growth and yield components of cultivar Cape Fear. Plant Dis. 87:259-262.

Sanderlin, R.S. and R.A. Melanson. 2006. Transmission of Xylella fastidiosa through pecan rootstock. HortScience 41:1455-1456.
Sanderlin, R.S. and R.A. Melanson. 2008. Reduction of Xylella fastidiosa transmission through pecan scion wood by hot-water treatment. Plant Dis. 92:1124-1126.

Sanderlin, R.S. and R.A. Melanson. 2010. Insect transmission of Xylella fastidiosa to pecan. Plant Dis. 94:465-470.

$\mathrm{Xu}, \mathrm{X}$., H. Huang, and J. Lu. 2002. Investigating the Xylella fastidosa in Pierce's disease resistant and susceptible grapevines. Proc. Fla. State Hort. Soc. 115:105-108. 